\title{
GCU
}

Glasgow Caledonian

University

University for the Common Good

\section{Comparing safety culture and learning culture}

Littlejohn, Allison; Lukic, Dane; Margaryan, Anoush

Published in:

Risk Management

DOI:

10.1057/rm.2015.2

Publication date:

2014

Document Version

Author accepted manuscript

Link to publication in ResearchOnline

Citation for published version (Harvard):

Littlejohn, A, Lukic, D \& Margaryan, A 2014, 'Comparing safety culture and learning culture', Risk Management, vol. 16, no. 4, pp. 272-293. https://doi.org/10.1057/rm.2015.2

\section{General rights}

Copyright and moral rights for the publications made accessible in the public portal are retained by the authors and/or other copyright owners and it is a condition of accessing publications that users recognise and abide by the legal requirements associated with these rights.

Take down policy

If you believe that this document breaches copyright please view our takedown policy at https://edshare.gcu.ac.uk/id/eprint/5179 for details of how to contact us. 
Original Article

\title{
Comparing safety culture and learning culture
}

\author{
Allison Littlejohn ${ }^{a, *}$, Dane Lukic ${ }^{b}$ and Anoush Margaryan ${ }^{c}$ \\ ${ }^{a}$ The Open University, Walton Hall, Milton Keynes, MK7 6AA, UK. \\ E-mail: Allison.Littlejohn@open.ac.uk \\ bGlasgow Caledonian University - GCU London, 40-48 Fashion Street, \\ Spitalfields, London, E1 6PX, UK. \\ ${ }^{\mathrm{C} C}$ aledonian Academy, Glasgow Caledonian University, Cowcaddens Road, \\ Glasgow, G4 OBA, UK. \\ *Corresponding author.
}

\begin{abstract}
This article examines the alignment of learning and safety culture in organisations. It tests the hypothesis that factors that indicate a good learning culture might also signify good safety and vice versa. The hypothesis was tested through an intensive literature review. Areas of alignment of learning culture and safety culture were identified. Six components of learning culture and safety culture can be measured by the same instrument. These components form guiding principles for measurement of safety culture and learning culture. Another eight component areas were identified where learning culture and safety culture partially align. Four further components were found to be relevant to either safety culture or learning culture and do not align. Overall, there is a relationship between learning culture and safety culture, but gauging one does not provide a reliable measure of the other.
\end{abstract}

Risk Management (2015) 16, 272-293. doi:10.1057/rm.2015.2

Keywords: safety; learning; culture; organisation

\section{Introduction: The Relationship between Safety and Learning Culture}

I t is widely acknowledged that safety and learning are both critical elements in creating a safe working environment. On the surface, safety culture and learning culture seem fundamentally different, yet on closer inspection there are remarkable similarities. Safety and learning culture are 
ethereal, tacit and embedded in everyday practice. They are customarily difficult to conceptualise and measure (Flin et al, 2000; Marsick and Watkins, 2003). However, there have been advances in the identification and measurement of key factors that indicate positive safety and learning culture, potentially improving the practical implementation of both.

The focus on culture across the learning and safety domain is grounded in a more general shift in organisationals towards exploring social and environmental factors that impact work. The terms culture and climate are sometimes used interchangeably in relation to safety and learning in the workplace. However, some studies have delineated these terms such that culture embodies values, beliefs and underlying assumptions, whereas climate describes the perceptions of the workforce in relation to the organisational 'ambiance' (González-Romá et al, 1999; Flin et al, 2000). This means that culture is a relatively stable, overarching feature of an organisation. Climate, on the other hand, is measured through workforce attitudes and perceptions that evolve and can be different when measured at any given point in time. Climate evolves in relation to culture and can therefore be viewed as a sub-set or feature of culture. Culture is normally viewed and measured through observable indicators (Flin et al, 2000). However, these indicators tend to be multi-faceted, tacit and complex. Therefore safety culture and learning culture are difficult to observe and measure directly. Nevertheless, culture is a useful lens through which to conceptualise safety and learning in the workplace.

The ways in which safety is perceived has evolved to aid organisations in the operationalisation of employee well-being and the creation of safer workspaces (Dedobbeleer and Béland, 1991; Cooper, 2000; Glendon and Stanton, 2000). Early conceptualisations of safety focused on the development of technical solutions. As new and safer mechanical systems developed rapidly, safety science tended to focus on technical malfunction. As mechanical systems improved, attention turned towards human error and human operational problems, rather than technical malfunctions. Unsafe practices and judgements are still viewed as a key source of system breakdown. Other sources of errors and accidents are socio-technical factors, which relate to the interaction between human and technical factor. Over the past decade, culture has became a critical factor in safety science and organisational psychology research as a means of interpreting incidents and understanding safety in organisations.

Safety culture is difficult to measure for all sorts of reasons. First, the measurement can be difficult where cause and effect is not straightforward to identify. Second, there are legal implications that restrict the measurement of safety culture. These legal associations are not so significant in learning culture, where there are far fewer legal constraints. Therefore learning culture appears to provide a simpler means of conceptualising the social and organisational factors that support the development of knowledge and skills in the workplace (Marsick and Watkins, 2003; Škerlavaj et al, 2007). Learning is significant in 
an era of continual change and innovation and is often used as a mechanism to stimulate creativity and originality (Martins and Terblanche, 2003). However organisational learning culture research typically is weak in identifying the specific processes or actions that make the learning effective (Engeström, 2001). New and improved methods and mechanisms for the measurement of learning culture and safety culture would undoubtedly help organisations improve learning and create safer workplace environments.

One way to improve the measurement of safety and learning culture could be to identify common factors. Factors that indicate an affirmative learning culture may point to good safety. Similarly, factors that indicate a positive safety culture may signify good learning. Any association of safety culture and learning culture measurement could be helpful for organisations. However, the relationship between learning culture and safety culture is not well understood. Interdisciplinary research across these fields has been limited (Lukic et al, 2010). To improve measurement methods, this study explored whether and in what ways safety and learning culture interrelate, specifically examining to what extent they occupy the same conceptual space. Drawing on literature spanning a number of disciplines, the aim was to identify whether and how measures of learning culture could be used to assess safety culture and vice versa.

This research identifies which factors of learning culture and safety culture are aligned. It examines whether and how measures of learning culture could indicate good safety and vice versa. The study contributes to organisational practice by identifying key principles that can be used by organisations to streamline safety and learning culture. The analysis advances the theoretical understanding of learning culture and safety culture by aligning key constructs across two disciplines that are usually unrelated, laying a foundation for future empirical studies.

The article begins with a detailed review of safety culture and learning culture literature, explaining how relevant papers from both areas were sourced, selected and summarised. The article then classifies key indicators of learning culture and safety culture abstracted from these articles. The method used to synthesise these key indicators into broad themes for learning culture and for safety culture is outlined. These broad themes are compared and aligned across the safety culture-learning culture nexus. Finally, the article concludes by defining principles for effective learning and safety culture.

\section{Method}

Our starting point for drawing together ideas and concepts related to organisational learning and safety was to carry out a systematic literature review in both disciplines. Key indicators of learning culture and safety culture were identified 
and compared through a systematic literature review and synthesis (Levac et al, 2010). The method comprised four phases:

Phase 1: Literature search. Two extensive literature searches were implemented, one on safety and the other on organisational learning. The aim was to identify relevant articles with indicators or measures of learning culture or safety culture.

Phase 2: Identification of indicators. The indicators of learning culture or safety culture identified in the review articles were abstracted and listed.

Phase 3: Analysis and synthesis of indicators. The indicators of learning culture or safety culture were grouped into broad themes.

Phase 4: Comparison of indicators of learning culture and safety culture. The broad themes (spanning learning culture and safety culture) were compared first to ascertain potential alignment across the learning culture-safety culture nexus and second to identify specific indicators that were not aligned.

Through examination of the alignment of factors that indicate positive safety and learning culture, the study identified whether measures of learning culture may indicate the quality of safety culture within organisations and vice versa. The project phases are described in detail in the following sections.

\section{Literature search}

The first goal of the research was to identify factors that indicate a positive learning or safety culture. Two in-depth literature searches were carried out. One search focused on finding relevant papers with key indicators of learning culture, while a second search sourced papers with indicators of safety culture. Articles were sourced using search engines CSA Illumina and Google Scholar with specific keywords. The following search keywords combinations were used to source papers on learning culture: ('learning culture'/'learning climate') + (attributes/ descriptors $)+\left(\right.$ instrument/measure* ${ }^{*}$. In the second search, the following keywords combinations were used to source papers on safety culture: ('safety culture'/'safety climate') + (attributes/factors/descriptors) + (instrument/ measure*/survey).

The key criterion for selecting articles was that the papers included either indicators of safety culture or of learning culture. Empirical papers and review papers were incorporated only if they included some key indicators. From an initial (extended) list, a shortlist was created using a two-stage filtering process. Initially, non-relevant papers were filtered out by reading the abstracts. All remaining papers were then examined to identify and abstract the key indicators. A number of articles were discarded at the second stage of filtering, since these papers did not focus on safety culture or learning culture or did not include indicators of either.

A total of 51 articles on safety culture were sourced. Thirty-four of these papers were shortlisted, reviewed and summarised. Seventeen were discarded 
since they did not meet the shortlisting criteria or were not accessible. A total of 55 articles on learning culture were sourced. Fourteen were shortlisted, reviewed and summarised. The remaining papers were discarded either because they did not meet the shortlisting criteria or were not accessible.

This means that a total of 48 relevant papers were identified, reviewed and summarised. These summaries were used to pinpoint factors that were indicators of learning culture or of safety culture.

\section{Identification of indicators}

In phase two of the study, specific indicators of safety culture and learning culture were identified and abstracted from the 48 article summaries. This analysis exposed two distinct types of indicators:

(a) Broad indicators of learning culture and safety culture such as 'senior management commitment' (for safety culture), or 'promoting dialogue and inquiry' (for learning culture).

(b) Narrow indicators. These were often items within questionnaire instruments in empirical studies (for example, 'I can discuss problems in work with my workmates when I need' for learning culture, or 'all colleagues understand emergency response' for safety culture).

A list of reviewed articles with the number of indicators and measures identified for each is included in Table 1.

\section{Analysis and synthesis of indicators}

Broad and narrow indicators of learning culture and safety culture were analysed and grouped into themes, as illustrated in Table 2. Themes include commitment, collaboration, workplace conditions and so on. Two distinct thematic analyses were carried out - one for learning culture and one for safety culture. Analysis was completed by colour-coding the indicators depending on which article the indicator was abstracted from, which construct the indicator referred to (safety culture or learning culture), and the type of indicator (general indicator or specific measure). The indicators were grouped into emergent themes and then the results were transferred to a database.

A second iteration of the analysis was carried out to refine the emerging themes and to check for reliability. The themes were refined by re-examining each indicator. Groupings were discussed and refined by three researchers to reach consensus over each individual categorisation. Any disparity around the categorisation of a specific indicator within a particular theme was resolved through team discussion and negotiation. One output from this phase of the analysis was a number of learning culture themes, each comprising key indicators of learning culture. Another output was a number of safety culture 
Table 1: Indicators identified from the literature

\begin{tabular}{|c|c|c|c|}
\hline Article & Constructs & $\begin{array}{l}\text { Number of general } \\
\text { indicators identified }\end{array}$ & $\begin{array}{l}\text { Number of specific } \\
\text { measures identified }\end{array}$ \\
\hline & Safety culture & 0 & 4 \\
\hline Bourne and Franco-Santos, 2010 & Learning culture & 0 & 6 \\
\hline $\begin{array}{l}\text { Cegarra-Navarro and } \\
\text { Rodrigo-Moya, } 2007\end{array}$ & Learning culture & 0 & 6 \\
\hline Clarke, 1999 & Safety culture & 2 & 24 \\
\hline Clarke, 2005 & Learning culture & 5 & 26 \\
\hline Cooper, 2000 & Safety culture & 3 & 0 \\
\hline Coyle et al, 1995 & Safety culture & 8 & 29 \\
\hline Dedobbeleer and Béland, 1991 & Safety culture & 9 & 9 \\
\hline Díaz and Cabrera, 1997 & Safety culture & 5 & 0 \\
\hline Evans et al, 2007 & Safety culture & 9 & 18 \\
\hline Flin et al, 2000 & Safety culture & 5 & 0 \\
\hline Fogarty and Buikstra, 2008 & Safety culture & 7 & 0 \\
\hline France et al, 2010 & Safety culture & 2 & 2 \\
\hline Gibbons et al, 2006 & Safety culture & 1 & 79 \\
\hline Glendon and Stanton, 2000 & Safety culture & 4 & 0 \\
\hline Glendon and Litherland, 2001 & Safety culture & 2 & 3 \\
\hline Grote, 2008 & Safety culture & 0 & 60 \\
\hline Harvey et al, 2001 & Safety culture & 4 & 2 \\
\hline Harvey et al, 2004 & Safety culture & 7 & 1 \\
\hline Håvold and Nesset, 2009 & Safety culture & 13 & 4 \\
\hline Hofmann and Stetzer, 1998 & Safety culture & 0 & 16 \\
\hline Høivik et al, 2009 & Safety culture & 6 & 0 \\
\hline Johnson, S. E. (2007) & Safety culture & 3 & 0 \\
\hline Johnston and Hawke, 2002 & Learning culture & 5 & 0 \\
\hline Kath et al, 2010 & Safety culture & 6 & 0 \\
\hline Lähteenmäki et al, 2001 & Learning culture & 3 & 20 \\
\hline Lawrie et al, 2006 & Safety culture & 1 & 28 \\
\hline Lee, 1998 & Safety culture & 4 & 4 \\
\hline Leung, 2006 & Learning culture & 0 & 12 \\
\hline Lin et al, 2008 & Safety culture & 14 & 21 \\
\hline Lofquist et al, 2011) & Safety culture & 0 & 3 \\
\hline Marsick and Watkins, 2003 & Learning culture & 4 & 0 \\
\hline Mikkelsen and Grønhaug, 1999 & Learning culture & 0 & 70 \\
\hline O’Connor et al, 2011 & Safety culture & 0 & 5 \\
\hline Olsen, 2010 & Safety culture & 0 & 9 \\
\hline Pearn et al, 1995 & Learning culture & 6 & 0 \\
\hline Pedler et al, 1996 & Learning culture & 11 & 0 \\
\hline Popper and Lipshitz, 2000 & Learning culture & 9 & 0 \\
\hline Probst, 2004 & Safety culture & 9 & 0 \\
\hline Sambrook and Stewart, 2000 & Learning culture & 15 & 1 \\
\hline Tarrini, M. 2004. & Learning culture & 0 & 68 \\
\hline Varonen and Mattila, 2000 & Safety culture & 4 & 0 \\
\hline Vinodkumar and Bhasi, 2009 & Safety culture & 6 & 46 \\
\hline Westerberg and Hauer, 2009 & Learning culture & 6 & 26 \\
\hline Wiegmann et al, 2004 & Safety culture & 5 & 0 \\
\hline Williamson et al, 1997 & Safety culture & 6 & 21 \\
\hline Wu et al, 2010 & Safety culture & 3 & 12 \\
\hline Zohar, 2010 & Safety culture & 5 & 3 \\
\hline
\end{tabular}


Table 2: Aligned themes across learning culture and safety culture

\begin{tabular}{|c|c|}
\hline Theme & Safety culture \\
\hline $\begin{array}{l}\text { Open } \\
\text { Communication }\end{array}$ & $\begin{array}{l}\text { Safety knowledge (tacit and explicit) and safety targets are } \\
\text { shared across the organisation. Communication is open } \\
\text { (formal and informal) and multidirectional. Effective systems } \\
\text { are in place to enable knowledge sharing (Hofmann and } \\
\text { Stetzer, 1998; Glendon and Stanton, 2000; Glendon and } \\
\text { Litherland, 2001; Arboleda et al,2003; Harvey et al, 2004; } \\
\text { Probst, 2004; Wiegmann et al, 2004; Gibbons et al, 2006; } \\
\text { Evans et al, 2007; Grote, 2008; Fogarty and Buikstra, 2008; } \\
\text { Lin et al, 2008; Håvold and Nesset, 2009; Vinodkumar and } \\
\text { Bhasi, 2009; Lofquist et al, 2011). } \\
15 / 34^{\mathrm{a}}\end{array}$ \\
\hline $\begin{array}{l}\text { Employee } \\
\text { empowerment }\end{array}$ & $\begin{array}{l}\text { Employees have autonomy, are involved in decision-making in } \\
\text { relation to safety and encouraged to make suggestions to } \\
\text { improve safety. Workers are encouraged to question unsafe } \\
\text { practices and have the authority to stop such practices } \\
\text { (Williamson et al, 1997; Hofmann and Stetzer, 1998; Lee, } \\
\text { 1998; Glendon and Stanton, 2000; Wiegmann et al, 2004; } \\
\text { Gibbons et al, 2006; Lawrie et al, 2006; Grote, 2008; Lin } \\
\text { et al, 2008; Vinodkumar and Bhasi, 2009; Kath et al, 2010; } \\
\text { Olsen, 2010) }\end{array}$ \\
\hline
\end{tabular}

Collaboration

\section{$12 / 34$}

Industrial operation can only be productive when it is safe. Productive operation requires effective work within and across teams so that everyone collaborates to improve safety (Lawrie et al, 2006; Grote, 2008; France et al, 2010; Olsen, 2010).

\section{Learning culture}

There are multiple open channels of communication to allow for effective information flow. There are systems in place to capture and share relevant knowledge across the company (Pedler et al, 1996; Popper and Lipshitz, 2000; Lähteenmäki et al, 2001; Marsick and Watkins, 2003; Tarrini, 2004; Clarke, 2005; Leung, 2006; Cegarra-Navarro and Rodrigo-Moya, 2007; Westerberg and Hauer, 2009).

\section{$9 / 14$}

Organisations empower employees to exercise their ability to actively engage in learning (Pedler et al, 1996; Mikkelsen and Grønhaug, 1999; Lähteenmäki et al, 2001; Johnston and Hawke, 2002; Marsick and Watkins, 2003; Clarke, 2005; Leung, 2006; Westerberg and Hauer, 2009). Watkins,

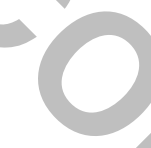

There are opportunities for collaboration (within and outside the company) and opportunities for individuals to develop teamwork skills (Pedler et al, 1996; Lähteenmäki et al, 2001; Johnston and Hawke, 2002; Marsick and Watkins, 2003; Clarke, 2005; Westerberg and Hauer, 2009). 
Alignment of

espoused and

enacted priorities

Internal systemic

alignment

Management

Enacted safety behaviours are aligned with espoused priorities (Williamson et al, 1997; Zohar, 2010).

\section{$2 / 34$}

Safety policy, procedure and rules are consistent (Wiegmann et al, 2004; Lawrie et al, 2006; Vinodkumar and Bhasi, 2009; Zohar, 2010).

Management prioritises safety, welcomes opinions of employees, follows safety rules, tackles unsafe practices, allocates sufficient resources, clearly understands safety implications of operational issues (Dedobbeleer and Béland, 1991; Coyle et al, 1995; Díaz and Cabrera, 1997; Williamson et al, 1997; Hofmann and Stetzer, 1998; Flin et al, 2000; Glendon and Stanton, 2000; Varonen and Mattila, 2000, Harvey et al, 2001; Harvey et al, 2004; Wiegmann et al, 2004; Gibbons et al, 2006; Lawrie et al, 2006; Evans et al, 2007; Fogarty and Buikstra, 2008; Grote, 2008; Lin et al, 2008; Håvold and Nesset, 2009; Høivik et al, 2009;

Vinodkumar and Bhasi, 2009; France et al, 2010; Kath et al, 2010; Olsen, 2010; Zohar, 2010; O’Connor et al, 2011).

$$
25 / 34
$$

Espoused priorities for learning and employees' learning behaviours are aligned (Lähteenmäki et al, 2001; Clarke, 2005; Leung, 2006; Bourne and Franco-Santos, 2010).

$4 / 14$

Internal policies, systems and procedures are aligned to encourage effective learning (Lähteenmäki et al, 2001; Leung, 2006; Westerberg and Hauer, 2009).

3/14

Managers have the commitment and competences to support learning (Pearn et al, 1995; Popper and Lipshitz, 2000; Sambrook and Stewart, 2000; Lähteenmäki et al, 2001; Clarke, 2005; Westerberg and Hauer, 2009).

${ }^{a}$ The number of articles out of the total number reviewed articles for safety culture or for learning culture. 
themes, each with a number of associated indicators of safety culture. A synthesised summary statement of these themes was created.

In the Phase 3 of the study, these emergent themes of learning culture and safety culture were analysed to identify alignment across the learning culturesafety culture nexus.

\section{Comparison of indicators of learning culture and safety culture}

The final phase of the study was a thematic alignment across the safety culturelearning culture nexus. The learning culture themes were reviewed and compared with the safety culture themes. Synthesised summary statements and individual indicators (grouped under each theme) were used to determine the degree of alignment across the themes. Three researchers carried out the thematic alignment independently. The results were compared and any disagreement was resolved through debate and discussion. The output was the set of aligned themes outlined in Table 2 and described in the following section.

\section{Results and Discussion}

This study identified some alignment of factors across the safety culturelearning culture nexus as follows:

- six themes of safety culture and learning culture were aligned (Table 2);

- eight themes were partially aligned, with a lesser degree of association (Table 3); and

- four themes were relevant only to safety culture or learning culture, not both (Table 4).

\section{Areas of full alignment between safety culture and learning culture}

Six themes of safety culture and learning culture have a degree of association. These themes are open communication, employee empowerment, collaboration, alignment of espoused and enacted priorities, internal systemic alignment and management. These themes are summarised in Table 2 . The table indicates the number of articles representing each theme (out of the total number of papers reviewed).

Open Communication is an important theme bridging safety culture and learning culture. For a positive safety culture it is important that managers and supervisors encourage open communication (Hofmann and Stetzer, 1998; Kath et al, 2010). Employees have to be able to discuss issues cooperatively with managers and peers. Any issues raised by personnel have to be communicated openly to other colleagues across the site (Gibbons et al, 2006). Similarly, a positive learning culture requires transparency through open dialogue operationalised through multiple channels of communication. Therefore both safety 
Table 3: Partially aligned themes for safety culture and learning culture

Motivation Safety behaviour is underpinned by individual motivation and job satisfaction (Lee, 1998; Glendon and Litherland, 2001; Harvey et al, 2001; Harvey et al, 2004; Lawrie et al, 2006; Grote, 2008; Håvold and Nesset, 2009; Høivik, et al, 2009; France et al, 2010; Zohar, 2010).

$$
10 / 34
$$

Recognition Systems are in place to reward employees for good safety performance, to and Reward gather ideas for improving safety and to allow employees to report ideas without fear of repercussions (Coyle et al, 1995; Hofmann and Stetzer, 1998; Clarke, 1999; Wiegmann et al, 2004; Gibbons et al, 2006; Grote, 2008; Vinodkumar and Bhasi, 2009)

$$
7 / 34
$$

Competence

Employees are competent in their job, use of safety equipment and know the safety rules and own responsibilities towards safety. There are welltrained safety officers in place (Coyle et al, 1995; Clarke, 1999; Flin et al, 2000; Harvey et al, 2001; Gibbons et al, 2006; Lawrie et al, 2006; Grote, 2008; Lin et al, 2008; Håvold and Nesset, 2009; Høivik et al, 2009; Vinodkumar and Bhasi, 2009).

$$
11 / 34
$$

Commitment Individuals are committed to safety and to caring for colleagues (Díaz and Cabrera, 1997; Williamson et al, 1997; Glendon and Stanton, 2000;

Varonen and Mattila, 2000; Harvey et al, 2001; Arboleda et al, 2003; Wiegmann et al, 2004; Gibbons et al, 2006; Lawrie et al, 2006; Grote, 2008; Fogarty and Buikstra, 2008; Vinodkumar and Bhasi, 2009; Høivik et al, 2009; Kath et al, 2010).$$
14 / 34
$$

Workplace conditions

Workplace conditions are adequate for safe work (Dedobbeleer and Béland, 1991; Coyle et al, 1995; Fogarty and Buikstra, 2008; Grote, 2008; Lin et al, 2008; Vinodkumar and Bhasi, 2009; Wu et al, 2010). $7 / 34$
Employees are inspired, confident, willing to learn, develop and embrace change (Pearn et al, 1995; Sambrook and Stewart, 2000; Lähteenmäki et al, 2001).

Systems are in place for rewarding learning (Clarke, 2005; Leung, 2006; Bourne and Franco-Santos, 2010).

Employees develop competences for learning as well as job-specific competences (Popper and Lipshitz, 2000; Lähteenmäki et al, 2001; Clarke, 2005).

The organisation demonstrates commitment towards employees' learning (Sambrook and Stewart, 2000; Johnston and Hawke, 2002; Clarke,

2005; Leung, 2006).

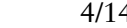

Workplace conditions are conducive to learning (Sambrook and Stewart, 2000; Lähteenmäki et al, 2001; Johnston and Hawke, 2002; Clarke, 2005).

$4 / 14$ 
Table 3: (Continued)

Risk Accurate risk assessment, prioritisation of risks, awareness of own risktaking actions and reactions to other risk-taking behaviours

(Dedobbeleer and Béland, 1991; Díaz and Cabrera, 1997; Williamson et al, 1997; Hofmann and Stetzer, 1998; Lee, 1998; Flin et al, 2000;

Harvey et al, 2001; Harvey et al, 2004; Lin et al, 2008; Vinodkumar and Bhasi, 2009; Wu et al, 2010; O'Connor et al, 2011).

$$
12 / 34
$$

Opportunities There are opportunities to discuss and learn from safety issues.

for learning Information is used to improve safety. Safety training covers a sufficient range of skills, knowledge and behaviours (Dedobbeleer and Béland, 1991; Grote, 2008; Håvold and Nesset, 2009; Vinodkumar and Bhasi, 2009; Olsen, 2010).

$$
5 / 34
$$

Policy and Adequate and clear safety policy and procedures are in place. procedures

Accounte and clear safety policy and procedures are in place. 2000; Varonen and Mattila, 2000; Glendon and Litherland, 2001; Probst, 2004; Gibbons et al, 2006; Lawrie et al, 2006; Evans et al, 2007 Fogarty and Buikstra, 2008; Grote, 2008; Lin et al, 2008; Wu et al, 2010).
Risk taking is encouraged and mistakes are accepted and viewed as an opportunity for learning (Sambrook and Stewart, 2000; Lähteenmäki et al, 2001; Westerberg and Hauer, 2009; Bourne and Franco-Santos, 2010).

A wide range of opportunities for learning are available (Pedler et al, 1996; Popper and Lipshitz, 2000; Lähteenmäki et al, 2001; Marsick and Watkins, 2003; Leung, 2006).

$5 / 14$

Policies and procedures for learning are developed in an agile and participatory way (Pedler et al, 1996; Popper and Lipshitz, 2000; Lähteenmäki et al, 2001; Clarke, 2005; ; Cegarra-Navarro and Rodrigo-Moya, 2007) 
Table 4: Non-aligned themes for safety culture and learning culture

\begin{tabular}{|c|c|c|}
\hline Theme & Safety culture & Learning culture \\
\hline $\begin{array}{l}\text { Social } \\
\quad \text { regulation }\end{array}$ & $\begin{array}{l}\text { Social regulation of safety behaviour can occur horizontally (between peers) and vertically } \\
\text { (between managers and employees) (Gibbons et al, 2006; Grote, 2008; Høivik et al, 2009; } \\
\text { O'Connor et al, 2011). }\end{array}$ & $\mathrm{n} / \mathrm{a}$ \\
\hline $\begin{array}{l}\text { Safety versus } \\
\text { Productivity }\end{array}$ & $\begin{array}{l}\text { Companies should align productivity and safety. Investing in safety leads to long-term profit } \\
\text { (Díaz and Cabrera, 1997; Williamson et al, 1997; Clarke, 1999; Flin et al, 2000; Gibbons et } \\
\text { al, 2006; Lawrie et al, 2006; Høivik et al, 2009; Grote, 2008; Lin et al, 2008; Håvold and } \\
\text { Nesset, 2009; Kath et al, 2010; O’Connor et al, 2011). }\end{array}$ & $\mathrm{n} / \mathrm{a}$ \\
\hline Equipment & $\begin{array}{l}\text { Appropriate safety equipment is available and equipment is up-to-date and well maintained } \\
\text { (Dedobbeleer and Béland, 1991; Coyle et al, 1995; Díaz and Cabrera, 1997; Hofmann and } \\
\text { Stetzer, 1998; Clarke, 1999; Evans et al,2007; Grote, 2008; Vinodkumar and Bhasi, 2009). } \\
\text { 9/34 }\end{array}$ & $\mathrm{n} / \mathrm{a}$ \\
\hline Innovation & $\mathrm{n} / \mathrm{a}$ & $\begin{array}{l}\text { The organisation encourages new ideas (Clarke, } \\
\text { 2005; Westerberg and Hauer, 2009; Bourne and } \\
\text { Franco-Santos, 2010). } \\
\text { 3/14 }\end{array}$ \\
\hline
\end{tabular}


culture and learning culture ideally are underpinned by communication processes and systems that capture and share and evolve relevant knowledge across the organisation. This knowledge improves safety and learning through purposeful use instigated by personnel

Employee empowerment was identified as another critical factor contributing to safety and learning culture (Coyle et al, 1995; Gibbons et al, 2006). An empowered attitude increases each individual's motivation to 'make a difference' and 'go beyond the call of duty', taking responsibility for safety (through an individual's safe operations) and learning (by individuals connecting with and contributing to organisational knowledge). In safety culture, employee empowerment usually means personnel have a 'substantial voice in safety decisions, have the leverage to initiate and achieve safety improvements, hold themselves and others accountable for their actions, and take pride in the safety record of their organization' (Wiegman et al, 2004, p. 120). Workers should be encouraged to question unsafe practice and have the authority to stop dangerous actions. Similarly, for learning culture organisations should empower workers to exercise active agency for learning. Employees should make decisions, suggest ideas and take a critical view of the organisation (Westerberg and Hauer, 2009).

Another shared theme is collaboration. From the literature we identified that safety and learning should be a collaborative task shared by employees across each organisation (Lähteenmäki et al, 2001; France et al, 2010). Collaboration is critical for safety, as safe and productive operation requires effective work practices both within and across teams. Learning also requires opportunities for collaboration both within and outside the organisation to develop team and groupwork skills. Collaboration is most effective when individuals have confidence in colleagues' knowledge and expertise. Mutual support in achieving collaborative goals is essential for a positive safety and learning culture (Grote, 2008; Westerberg and Hauer, 2009).

The alignment of enacted and espoused priorities is a critical theme bridging safety culture and learning culture (Argyris and Schon, 1978; Wiegmann et al, 2004). This theme refers to the alignment between an employee's intentions and their actions: what people do and their intended outcome (Leung, 2006; Zohar, 2010). If an employee carries out a learning activity with the intention to achieve accreditation, rather than to learn, the result could be surface, rather than deep learning. Similarly, if an employee reports a colleague who is behaving in an unsafe manner with malicious intent, rather than to improve safety, the outcome may be harmful. Therefore individual and organisational values have to be aligned with professional practice.

The managers' role in facilitating and maintaining a positive culture featured prominently in the safety culture and learning culture literature. Management response to and continued involvement in employee initiatives is essential for maintaining employee motivation and cooperation (Gibbons et al, 2006). For a 
positive safety culture managers have to prioritise safety and allocate sufficient resources. To achieve this goal, managers have to understand clearly the safety implications of operational factors, including their own attitude, behaviours and competencies. They should adopt safe practice themselves and exemplify positive safety behaviour. Managers should be receptive of employees' concerns, suggestions and criticism and should be able and willing to challenge unsafe practices (Hofmann and Stetzer, 1998). Similarly, for a positive learning culture managers should exhibit the commitment and competences to encourage and support learning.

Internal systemic alignment featured prominently in both safety and learning culture literature (Vinodkumar and Bhasi, 2009; Westerberg and Hauer, 2009). Organisational environments comprise largely of policies, procedures, and practices and a positive safety climate requires alignment across these components (Zohar, 2010). Safety and learning policy, procedure and rules sometimes are not aligned with each other. One example of safety misalignment is where employees are expected to report incidents, yet contractors lose their contract if they are involved in a number of incidents. This misalignment may result in contractors not reporting every incident. Similarly, learning assessments may not provide an accurate measure of competency. For example, writing a report on how to install equipment is not an authentic measure of ability. Integrating learning and safety actions within an overarching, organisational system is one way to avoid inconsistencies within organisations (Flood and Romm, 1996).

A number of partially aligned themes were also identified through this study.

\section{Areas of partial alignment between safety culture and learning culture}

The analysis uncovered eight themes that partially aligned across safety and learning culture (see Table 3). Partially aligned themes include: motivation, recognition and rewards, competence, commitment, workplace condition, risk, opportunities for learning and policy and procedures. These themes were not completely aligned. The summary statements and individual indicators revealed similarities and differences across these constructs, illustrated in Table 3. Although these themes have some parallels, they are distinct across safety culture and learning culture. These similarities and differences are outlined below.

The study identified potential stark differences in an individual's motivations in terms of learning culture and safety culture. For example, self-development is a key motivation in learning culture (Lähteenmäki et al, 2001). However, in safety culture the primary concern is not only the well-being of oneself, but also the safety of others (Lawrie et al, 2006). In looking after others, an individual also takes care of his or herself.

The analysis pinpointed a significant motivation for employees across both safety culture and learning culture as reward and recognition. There is evidence 
that both safety culture and learning culture may be improved in organisations where robust reward and recognition systems are in place. However, the ways in which safety and learning are rewarded and encouraged in organisations is strikingly different. In the workplace, safety is an imperative that cannot be compromised (Coyle et al, 1995). Therefore constant, positive reward for safe behaviour is vital. By contrast, learning is usually viewed as desirable, but not always crucial. Employees' jobs are not automatically at risk where people do not engage in a positive learning culture. Therefore the ways in which rewards for safe practices and learning practices are implemented will be different.

In the literature, we identified a range of job-specific and meta-cognitive competencies that were critical for work (Clarke, 2005). The meta-cognitive competencies described in the organisational learning literature are similar to those outlined in the safety literature. These competencies include the ability of employees to judge their ability relative to others and their confidence to engage in learning or safety behaviours. However, there are also noticeable differences. Safety competencies are explicitly trained in organisations. There is an underlying assumption that employees may not have even the most basic of safety competencies; for example how to exit a building in the event of fire. By contrast, it is often assumed that personnel know how to learn, even though this is not always the case. Few initiatives are in place to allow employees to expand their learning competencies and learn how to learn.

Organisations and individuals have to demonstrate commitment to safety and to learning for effective safety and learning culture (Johnston and Hawke, 2002). However, in safety culture individual employees must demonstrate commitment to the safety of others. By contrast, learning is often viewed as an individual's goal. Therefore commitment to learning is seen by organisations as an individual trait, rather than a collective characteristic.

Individuals should be aware of the risk their actions entail for both safety and learning culture (Popper and Lipshitz, 2000; Glendon and Litherland, 2001). However, there is a stark contrast in risk taking in learning culture compared with safety culture. Risk taking is encouraged in learning culture but avoided in safety culture. It is essential that employees understand the potential consequences of risk-taking actions and manage risks appropriately for a positive safety culture.

Workplace conditions should be conducive for both learning and safety culture. Organisations should maintain optimal conditions for effective work. However, the literature signals that safety culture tends to be around a number of physical features of the workplace environment, including maintenance and housekeeping. By contrast, workplace conditions for learning culture focus on human actions and processes, including human resource activities, learning support and the organisation of work (Sambrook and Stewart, 2000).

Opportunities for learning are important. Positive safety and learning culture is encouraged when employees can identify and engage in formal and informal 
learning. There is evidence in the literature that organisational learning opportunities are both planned and unplanned. This is in stark contrast to the requirements for a positive safety culture, where 'unplanned' actions should be avoided. Another notable observation from the literature is that the content of safety culture and learning culture training tends to be different in nature: safety training tends to be specific while learning content can be either specific or generic (Håvold and Nesset, 2009).

There is clear evidence in the literature that in both in learning culture and safety culture policy and procedures are developed collaboratively and updated regularly (Cooper, 2000; Grote, 2008). However, there are some discernible differences. Safety policy and procedures are enforced, whereas learning policy and procedures are used more for guidance. Another variance is that safety procedures are more specific than learning procedures. Also notable is that policies around accountability are more prevalent in safety culture.

A number of other themes were identified from the analysis. Rather than bridging the learning-safety nexus, these themes related to either learning culture or safety culture.

\section{Areas of misalignment between safety culture and learning culture}

The analysis identified four themes limited to either safety culture or learning culture. Non-aligned themes include: social regulation, safety versus productivity, equipment and innovation. The themes are summarised in Table 4.

Innovation was a significant theme appearing regularly in the literature on learning culture, but was absent in the safety culture literature. One explanation could be that the sorts of risk-taking activities often required for innovation are at odds with the compliance aspect of safety culture (Vinodkumar and Bhasi, 2009). Therefore innovation and compliance are competing factors.

Social regulation was identified in the literature as an important aspect of safety culture. This prevalence of social regulation in safety could be due to the effect of each individual's practices and behaviours on other personnel (Gibbons et al, 2006). However, it seems easier for organisations to request individuals to obey safety rules (for example, 'hold the handrail' or 'wear your safety helmet') than to comply with learning (for example, 'learn this concept'). This could be because some facets of safety culture are behavioural, while learning is cognitive. We found indications where mandatory learning was viewed as critical, particularly in circumstances where employees have to work collaboratively in hazardous settings.

Safety versus productivity was a theme identified only in the safety culture literature, where balancing productivity and safety seems critical (Díaz and Cabrera, 1997; Håvold and Nesset, 2009). However, there was no evidence of a similar balance required in learning culture. In fact, research in professional learning evidenced that productivity is sometimes prioritised over learning, 
when employees are not given sufficient time to learn. It is possible that there is a strong link between learning and productivity that has not been evidenced through this analysis because there is too little empirical research in this area.

Equipment was a prominent theme in the safety culture literature (Grote, 2008), possibly influenced by early conceptualisations of safety focused on the development of technical solutions. By contrast, although the organisational learning literature indicated that workplace conditions should be conducive for learning, equipment was mentioned in few studies.

Aside setting theoretical foundation for future research, these outcomes have practical relevance for organisations, as discussed in the next section.

\section{Key Principles for Safety and Learning Culture}

Generally, this study identified themes bridging safety culture and learning culture:

- six themes where safety culture and learning culture are fully aligned (open communication, empowerment, collaboration, alignment of enacted and espoused priorities, management and internal systemic alignment),

- eight themes where safety culture and learning culture are partially aligned (motivation, recognition and rewards, commitment, competence, workplace conditions, risk, opportunities for learning and policy and procedures), and

- four themes that pertain only to safety culture or learning culture.

The analysis of alignment of these themes allowed the development of key principles for safety and learning culture. These principles were developed on the basis of the themes that align across learning culture and safety culture. The principles can be used to help companies implement and streamline safety and learning activities.

Positive safety and learning culture share are based on:

1. Open communication - Multiple, open channels of communication should be in place to allow for effective and multi-directional information flow. Effective systems should be implemented to capture and share relevant knowledge across the company.

2. Employee empowerment - Employees should be involved in decisionmaking around safety and learning. They should be encouraged to question practices and make suggestions about improvements in both safety and learning.

3. Collaboration - Opportunities should be available for collaboration within and across teams and employees should be supported in developing necessary teamwork skills.

4. Alignment of espoused and enacted priorities - Enacted behaviours should align with espoused policies, procedures and rules. 
5. Internal systemic alignment - Policies, procedures and rules should be consistent with each other.

6. Management-Managers should have the commitment and competences to encourage learning and safety, creating conditions necessary to implement safety principles (open communication, empowerment, collaboration, alignment of espoused and enacted priorities and internal systemic alignment).

Figure 1 illustrates these key principles and how they relate to the themes. From the literature, we identified four themes that are vital for safety and learning culture: open communication, employee empowerment, collaboration and alignment of espoused and enacted priorities. These four central themes are underpinned by two further themes: management and internal systemic alignment. Management is critical for facilitating good open communication, employee empowerment, collaboration and alignment of espoused and enacted priorities (Gibbons et al, 2006). Similarly, internal systemic alignment underpins open communication, employee empowerment, collaboration and alignment of espoused and enacted priorities (Flood and Romm, 1996). These aligned themes are at higher level of abstraction and generalisability than the non-aligned themes identified through this study. Overall, the higher the level of abstraction of the themes, the greater the degree of alignment between safety culture and learning culture.

These guiding principles can be used by safety managers to guide the development of policies and practices. Themes that are misaligned across learning culture and safety culture are equally important and should also be taken into consideration. Alignment across themes could be meaningful when

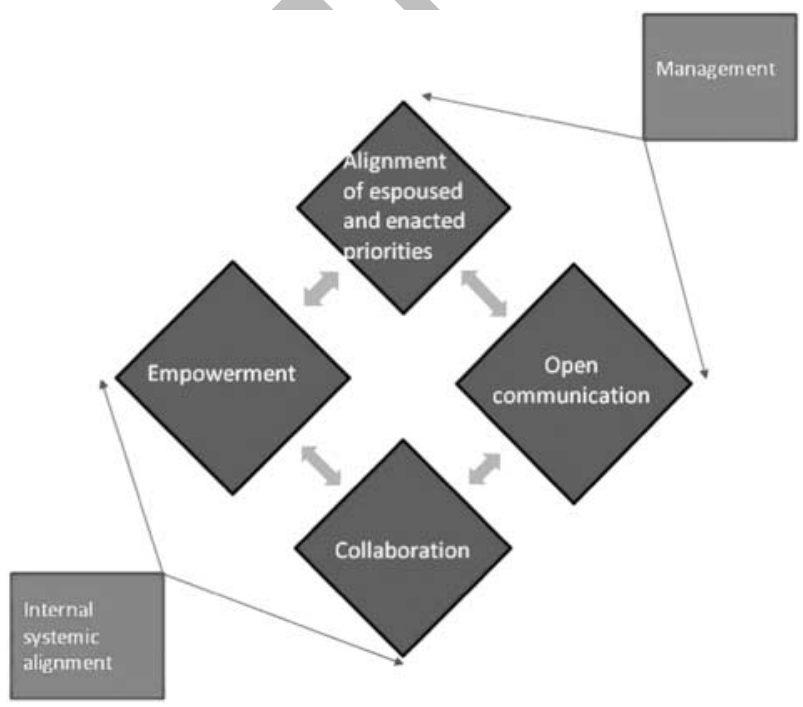

Figure 1: Principles for effective safety and learning culture. 
setting policy or strategy. However, it is less useful when operationalising or measuring learning culture and safety culture in practice.

Understanding the relationship between safety culture and learning culture is critical to improving organisational performance (Evans et al, 2007; Grote 2008; Lofquist et al, 2011). This study provides a baseline from which to understand the complex interrelationships across safety culture and learning culture.

\section{Acknowledgements}

This work was funded by BP International. The authors are grateful to Dr Urbain Bruyere (BP's Vice President, Operating Culture) who helped devise and test the hypothesis.

\section{References}

Arboleda, A., Morrow, P.C., Crum, M.R. and Shelley, M.C. (2003) Management practices as antecedents of safety culture within the trucking industry: Similarities and differences by hierarchical level. Journal of Safety Research 34(2): 189-197.

Argyris, C. and Schon, D.A. (1978) Organizational Learning: A Theory of Action Perspective. Reading, MA: Addison Wesley Longman Publishing Company.

Bourne, M. and Franco-Santos, M. (2010) Investors in People, Managerial Capabilities and Performance. Cranfield, UK: Cranfield School of Management.

Cegarra-Navarro, J.G. and Rodrigo-Moya, B. (2007) Learning culture as a mediator of the influence of an individual's knowledge on market orientation. The Service Industries Journal 27(5): 653-669.

Clarke, N. (2005) Workplace learning environment and its relationship with learning outcomes in healthcare organisations. Human Resource Development International $8(2): 185-206$.

Clarke, S. (1999) Perceptions of organizational safety: Implications for the development of safety culture. Journal of Organizational Behavior 20(2): 185-198.

Cooper, M.D. (2000) Towards a model of safety culture. Safety Science 36(2): 111-136.

Coyle, I.R., Sleeman, S.D. and Adams, N. (1995) Safety climate. Journal of Safety Research 26(4): 247-254.

Dedobbeleer, N. and Béland, F. (1991) A safety climate measure for construction sites. Journal of Safety Research 22(2): 97-103.

Díaz, R.I. and Cabrera, D.D. (1997) Safety climate and attitude as evaluation measures of organizational safety. Accident Analysis and Prevention 29(5): 643-650.

Engeström, Y. (2001) Expansive learning at work: Toward an activity theoretical reconceptualization. Journal of education and work 14(1): 133-156.

Evans, B., Glendon, A.I. and Creed, P.A. (2007) Development and initial validation of an aviation safety climate scale. Journal of Safety Research 38(6): 675-682.

Flin, R., Mearns, K., O’Connor, P. and Bryden, R. (2000) Measuring safety climate: Identifying the common features. Safety Science 34(1-3): 177-192.

Flood, R.L. and Romm, N.R.A. (1996) Contours of diversity management and triple loop learning. Kybernetes 25(7/8): 154-163. 
Fogarty, G.J. and Buikstra, E. (2008) A test of direct and indirect pathways linking safety climate, psychological health, and unsafe behaviours. International Journal of Applied Aviation Studies 8(2): 199-210.

France, D.J. et al (2010) Measuring and comparing safety climate in intensive care units. Medical Care 48(3): 279-284.

Gibbons, A.M., von Thaden, T.L. and Wiegmann, D.A. (2006) Development and initial validation of a survey for assessing safety culture within commercial flight operations. International Journal of Aviation Psychology 16(2): 215-238.

Glendon, A.I. and Litherland, D.K. (2001) Safety climate factors, group differences and safety behaviour in road construction. Safety Science 39(3): 157-188.

Glendon, A.I. and Stanton, N.A. (2000) Perspectives on safety culture. Safety Science 34(1-9): 193-214.

González-Romá, V., Peiró, J.M., Lloret, S. and Zornoza, A. (1999) The validity of collective climates. Journal of Occupational and Organizational Psychology 72(1): 25-40.

Grote, G. (2008) Diagnosis of safety culture: A replication and extension towards assessing 'safe' organizational change processes. Safety Science 46(3): 450-460.

Harvey, J., Bolam, H., Gregory, D. and Erdos, G. (2001) The effectiveness of training to change safety culture and attitudes within a highly regulated environment. Personnel Review 30(6): 615-636.

Harvey, J., Erdos, G., Jackson, H. and Dennison, S. (2004) Is safety culture in differing organizations the same thing? A comparison of safety culture measures in three organizations. Risk, Decision and Policy 9(4): 391-400.

Håvold, J.I. and Nesset, E. (2009) From safety culture to safety orientation: Validation and simplification of a safety orientation scale using a sample of seafarers working for Norwegian ship owners. Safety Science 47(3): 305-326.

Hofmann, D.A. and Stetzer, A. (1998) The role of safety climate and communication in accident interpretation: Implications for learning from negative events. Academy of Management Journal 41(6): 644-657.

Høivik, D., Tharaldsen, J.E., Baste, V. and Moen, B.E. (2009) What is most important for safety climate: The company belonging or the local working environment? - A study from the Norwegian offshore industry. Safety Science 47(10): 1324-1331.

Johnson, S.E. (2007) The predictive validity of safety climate. Journal of Safety Research 38(5): 511-521.

Johnston, K. and Hawke, J. (2002) Case Studies of Organisations with Established Learning Cultures. Leasbrook, Australia: National Centre for Vocational Education Research.

Kath, L.M., Marks, K.M. and Ranney, J. (2010) Safety climate dimensions, leader Member exchange, and organizational support as predictors of upward safety communication in a sample of rail industry workers. Safety Science 48(5): 643-650.

Lähteenmäki, S., Toivonen, J. and Mattila, M. (2001) Critical aspects of organisational learning research and proposals for its measurement. British Journal of Management 12(2): 113-129.

Lawrie, M., Parker, D. and Hudson, P. (2006) Investigating employee perceptions of a framework of safety culture maturity. Safety Science 44(3): 259-276.

Lee, T. (1998) Assessment of safety culture at a nuclear reprocessing plant. Work Stress 12(3): 217-237.

Leung, W.-C. (2006) The development of a learning organisation in Hong Kong: From design to implementation - The case of McDonald's Restaurants (H.K. Limited). DProf thesis, Middlesex University, London, UK. 
Levac, D., Colquhoun, H. and O'Brien, K.K. (2010) 'Scoping studies: Advancing the methodology', Implementation Science, 5(69) [online] http://www.implementationscience.com/content/pdf/1748-5908-5-69.pdf, accessed 18 December 2013.

Lin, S.-H., Tang, W.-J., Miao, J.-Y., Wang, Z.-M. and Wang, P.-X. (2008) Safety climate measurement at workplace in China: A validity and reliability assessment. Safety Science 46(7): 1037-1046.

Lofquist, E.A., Greve, A. and Olsson, U.H. (2011) Modeling attitudes and perceptions as predictors for changing safety margins during organizational change. Safety Science 49(3): 531-541.

Lukic, D., Margaryan, A. and Littlejohn, A. (2010) How organisations learn from safety incidents: A multifaceted problem. Journal of Workplace Learning 22(7): 428-450.

Marsick, V.J. and Watkins, K.E. (2003) Demonstrating the value of an organization's learning culture: The dimensions of the learning organization questionnaire. Advances in Developing Human Resources 5(2): 132-151.

Martins, E.C. and Terblanche, F. (2003) Building organisational culture that stimulates creativity and innovation. European Journal of Innovation Management 6(1): 64-74.

Mikkelsen, A. and Grønhaug, K. (1999) Measuring organizational learning climate a cross-national replication and instrument validation study among public sector employees. Review of Public Personnel Administration 19(4): 31-44.

O’Connor, P., Buttrey, S.E., O’Dea, A. and Kennedy, Q. (2011) Identifying and addressing the limitations of safety climate surveys. Journal of Safety Research 42(4): 259-265.

Olsen, E. (2010) Exploring the possibility of a common structural model measuring associations between safety climate factors and safety behaviour in health care and the petroleum sectors. Accident Analysis and Prevention 42(5): 1507-1516.

Pearn, M., Roderick, C. and Mulrooney, C. (1995) Learning Organisations in Practice. London/New York: McGraw-Hill.

Pedler, M., Burgoyne, J. and Boydell, T. (1996) The Learning Company: A Strategy for Sustainable Development. Cambridge: McGraw-Hill.

Popper, M. and Lipshitz, R. (2000) Organizational learning: Mechanisms, culture, and feasibility. Management Learning 31(2): 181-196.

Probst, T.M. (2004) Safety and insecurity: Exploring the moderating effect of organizational safety climate. Journal of Occupational Health Psychology 9(1): 3-10.

Sambrook, S. and Stewart, J. (2000) Factors influencing learning in European learning oriented organisations: Issues for management. Journal of European Industrial Training 24(2/3/4): 209-219.

Škerlavaj, M., Štemberger, M.I., Škrinjar, R. and Dimovski, V. (2007) Organizational learning culture - The missing link between business process change and organizational performance. International Journal of Production Economics 106(2): 346-367.

Tarrini, M. (2004) The development and application of a bespoke organisational learning competency framework in a global organisation. PhD thesis, Cranfield University, Cranfield, UK.

Varonen, U. and Mattila, M. (2000) The safety climate and its relationship to safety practices, safety of the work environment and occupational accidents in eight woodprocessing companies. Accident Analysis and Prevention 32(6): 761-769.

Vinodkumar, M.N. and Bhasi, M. (2009) Safety climate factors and its relationship with accidents and personal attributes in the chemical industry. Safety Science 47(5): 659-667.

Westerberg, K. and Hauer, E. (2009) Learning climate and work group skills in care work. Journal of Workplace Learning 21(8): 581-594. 
Wiegmann, D.A., Zhang, H., Von Thaden, T.L., Sharma, G. and Gibbons, A.M. (2004) Safety culture: An integrative review. The International Journal of Aviation Psychology 14(2): 117-134.

Williamson, A.M., Feyer, A., Cairns, D. and Biancotti, D. (1997) The development of a measure of safety climate: The role of safety perceptions and attitudes. Safety Science 25(1-3): 15-27.

Wu, T., Lin, C. and Shiau, S. (2010) Predicting safety culture: The roles of employer, operations manager and safety professional. Journal of Safety Research 41(5): 423-431.

Zohar, D. (2010) Thirty years of safety climate research: Reflections and future directions. Accident Analysis Prevention 42(5): 1517-1522. 